\title{
Buxaceae endémicas del Perú
}

\section{Blanca León ${ }^{1,2}$}

${ }^{1}$ Museo de Historia Natural, Av. Arenales 1256, Aptdo. 14-0434, Lima 14, Perú

2 Plant Resources Center, University of Texas at Austin, Austin TX 78712 EE.UU.

blanca.leon@mail.utexas.edu

\section{Resumen}

La familia Buxaceae es reconocida en el Perú por presentar un género, Styloceras, y tres especies (Brako \& Zarucchi, 1993; Ulloa Ulloa et al., 2004), todos arbustos. En este trabajo reconocemos un endemismo. Esta especie endémica se encuentra en la región Bosques Muy Húmedos Montanos, entre los 1800 y $1850 \mathrm{~m}$ de altitud. No está representada en el Sistema Nacional de Áreas Naturales Protegidas por el Estado.

Palabras claves: Buxaceae, Styloceras, Perú, endemismo, plantas endémicas.

\section{Abstract}

The Buxaceae are represented in Peru by three species in the genus Styloceras. (Brako \& Zarucchi, 1993; Ulloa Ulloa et al., 2004), all of them shrubs. Here we recognize one endemic species. This species has been found in the Very Humid Montane Forests region, between 1800 and 1850 m elevation, and has not been recorded in the Peruvian parks system.

Keywords: Buxaceae, Styloceras, Peru, endemism, endemic plants.

\section{Styloceras penninervium A.H. Gentry \& G. Aymard}

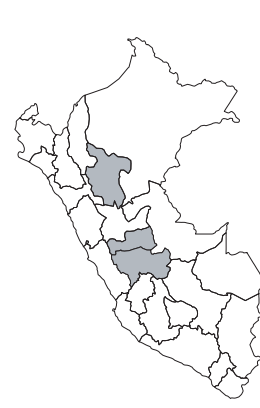

EN, B1ab(iii)

Publicación: Novon 3(2): 142, f. 1. 1993.

Colección tipo: F. Woytkowski 35497

Herbarios: MO.

Nombre común: Desconocido.

Registro departamental: JU, PA, SM.

Regiones Ecológicas: BMHM; 1800$1850 \mathrm{~m}$.

SINANPE: Sin registro.

Herbarios peruanos: CPUN (1), USM (1).

Observaciones: Árbol conocido de localidades dispersas, distantes entre ellas menos de $100 \mathrm{~km}$. Esta especie fue descrita de una planta recolectada en 1943 de la cuenca del Tulumayo; un segundo registro fue realizado en 1983 en la cuenca del Pozuzo. La deforestación es la principal amenaza a sus poblaciones. 